\title{
Editorial: Interactive electronic marketing and brand management
}

\section{SIGNS OF THE TIME}

As marketers, we make considerable use of technology in our dealings with customers. We are comfortable with the use of radio, broadcast television, cable and satellite television, the telephone, fax, electronic databases and computer-based ordering and payment systems (eg EFTPOS and ECR). These familiar technologies help us communicate with customers, assist in getting goods to market, and facilitate transaction, fulfilment and delivery processes. We are also very familiar with the role of computing technologies in the design, development and commercialisation of new products and services (eg CAD and CAM).

However, over a period of less than ten years a whole new genre of digital and interactive technologies has come to prominence in the commercial world. The best known of these and the most widely used to date is the Internet - the massive global network of interconnected packet-switched computer networks that facilitates interactive multimedia many-to-many communication between users. Communication is achieved through specific applications and environments, of which the World Wide Web is one example. The Internet also supports discussion groups (eg moderated and unmoderated mailing lists), brand communities and anonymous consumer profiling, communication systems (eg Internet Relay Chat, IRC), file transfer, electronic mail and global information access and retrieval systems. ${ }^{1}$

The most visible aspect of this technology - for marketers at least has been the creation and use of websites. These sites have provided a platform for the provision of information, advertising, communication and dialogue, and for order placement. For some products they even allow direct order fulfilment (eg news services and online music). The names behind these websites are a mixture of dedicated online businesses and dual-purpose online/offline businesses. Some are new ventures (eg ebay.com, handbag.com and wishlist.com.au), others have quite a heritage of techno-branding to draw upon (eg ibm.com and dell.com), and a few are providing textbook cases of integrated online/offline branding (eg orange.com and gap.com). Added to these sites are the new intermediaries - search engines, shopping robots and one-stop Web portals (eg yahoo.com, excite.com and aol.com), plus a new array of measurement services (eg mediametrix.com). These examples confirm that e-branding is a reality. They are names to be reckoned with.

Indeed, the Web has become an inescapable part of every marketer's life. Every organisation of note now has a website. Every person of note has a website. Every place of note has a site. In the wake of these developments have come a multitude of observers, commentators, advisers, consultants and - no doubt - a few charlatans, opportunists and adventures. Literally dozens of conferences, workshops and seminars have been convened: '2001 Faculty Consor- 
tium on Electronic Commerce', 'Internet World Conference', 'From Web Presence to Online Enterprise', 'Interactive TV Advertising' and 'WebBased Surveys and Online Market Research' are examples, drawn at random from my own mailbag, which illustrate the diverse range of issues being considered on a worldwide basis - everything from new business models to the impact on traditional media and new opportunities for market researchers.

Academic researchers have been quick to capitalise on these developments too. Dedicated journals have been launched, including the Quarterly Journal of Electronic Commerce, Interactive Marketing, the Journal of ComputerMediated Communication and the International Journal of Electronic Commerce. Over the past couple of years established marketing journals have been commissioning special issues particularly fine examples include the European Journal of Marketing (July 1998), the Journal of Advertising (March/April issues of 1997 and 1998) and Marketing Science (Winter 2000). Nor has the topic been ignored in the pages of the Journal of Brand Management with, for instance, insightful editorials by Patrick Barwise ${ }^{2}$ and Jean-Noel Kapferer. ${ }^{3}$ All this interest among researchers is not so surprising - the Internet originated in defence and academic research communities, and therefore those working in these communities have had more opportunity than most to reflect on developments as they have unfolded.

In recent years attempts have been made to codify and disseminate what we know about Internet marketing through courses and textbooks. Quick off the mark were general management and strategic management books such as 'Electronic Commerce: A Manager's Guide' ${ }^{4}$ and 'Electronic Commerce: The Strategic Perspective'. 5 Now we see an increasing number of more specialist texts, examples being 'Electronic Commerce: Strategies and Models for Business-to-Business Trading, ${ }^{6}$ 'Cybermarketing: How to Use the Internet to Market Your Goods and Services', 'Principles of Internet Marketing'8 and 'Electronic Marketing: Integrating Electronic Resources into the Marketing Process'. ${ }^{9}$ The latter two are particularly thorough, and replete with dozens of dot.com examples. Indeed, much of our thinking about Internet marketing rests on case histories, something that has been given more formal status in benchmarking studies (see for example Benchmark Communication ${ }^{10}$ and the 'best practice' section of Interactive Marketing). This also has been the preferred mode of thinking in essays, reports and books from leading consultants - for example, 'Brand Building on the Internet" ' and 'Blown to Bits: How the New Economics of Information Transforms Strategy'. ${ }^{12}$

Quite appropriately, websites have also been created in an attempt to bring together and codify what we know. Particularly important research sites are those maintained by Wharton (http://knowledge.wharton.upenn. edu), the Centre for eBusiness at MIT (http://ebusiness.mit.edu/forum/), the Future Media Research Programme at London Business School (http://www.london.edu/marketing/ future/), and eLab at Vanderbilt, which has been in operation since 1994 and is seen as something of a pioneer in this field (http://ecommerce.vanderbilt. $\mathrm{edu})$. 
Unfortunately, with all this activity in such a short space of time it is hard not to think in terms of gold-rushes and bandwagons. Also - for those with a more sinister and dismal view of economic history - bubbles, crashes and shakeouts come to mind too. Which leads to the questions posed in this particular special issue: for brand managers, does this add up to a whole new world? Or is it hyperbole? Are we watching the death-throes of brand management, or a rebirth? Those with long memories will recall the dire predictions for the future of brand management at the beginning of the $1990 s^{13}$ - ten years on we might well ask whether this was a premonition of things to come or, by contrast, bad futurology.

\section{IT IS A WHOLE NEW WORLD}

One view of these developments is that the Internet presents us with a whole new world. Marketing and marketers must rethink basic principles if they are to avoid going the way of the dinosaurs - typical are the sentiments of Jag Sheth and Rajendra Sisodia. ${ }^{14}$ In reviewing the state of marketing at the beginning of the new millennium, these authors assert that marketing is a context-driven discipline, and the context is changing radically, thus we need to question and challenge wellaccepted lawlike generalisations and principles. In the specific case of branding, McKinsey consultants Sandeep Dayal, Helene Landesberg and Michael Zeisser point out that:

\footnotetext{
'creating winning digital brands requires managers to reconsider how they view both the Internet and branding. Off-line brands have long thrived by delivering narrow
}

solutions to limited customer needs. Online, however, customers have learned to expect that the companies they patronize will meet a fuller spectrum of their needs and desires. To succeed on-line, those companies will have to create full-fledged Internet businesses, or digital brands, that can fulfil this expectation. ${ }^{15}$

In general, advocates of this view argue as follows.

- A totally new business model is required. Tinkering with our old models simply will not suffice.

- Technological developments are so rapid that forward planning with any certainty is no longer possible. The name of the game is flexibility, adaptability and an acceptance of continual change.

- Markets too are more uncertain, if not chaotic. For instance, technology is lowering barriers to entry and therefore many more players can enter almost any market, be it a local or a global market, be it mass or niche. In such a world, rather than build market share, it makes more sense to build 'share of wallet' with key customers.

- Winners will be those who can best capitalise on the interactive aspects of the Internet. This means a change in emphasis from oneto-many communications ('talking at consumers') to many-to-many communications ('a dialogue with consumers'). Traditional media are ill-equipped for dialogue, and those who rely on such traditional media will be at a severe disadvantage in the future.

- Power shifts from brand owners and distributors to consumers, reflecting the democratic character of the In- 
ternet. Whereas classical branding creates information asymmetries to the advantage of manufacturers, the Internet enables dispersed access to information. If there are any asymmetries, they will be to the advantage of consumers.

- Location is irrelevant, changing our notions of the physical separation of buyers and sellers and greatly reducing transaction costs.

- New growth economics apply, based on the management of 'knowledge assets'. Old-world notions of slow experience curves and lengthy depreciation cease to apply. Brand longevity counts for little. Indeed, it may be a handicap if it is associated too closely with traditionalism and a rear-view mirror of markets.

- Consumers and businesses insist on customised products, services and solutions. Gone is the landscape of well-defined, relatively homogeneous mass markets served by standardised branded products. Buying is more akin to buying off a list - according to one's own specifications - than choosing an all-purpose brand.

- Technology enables simultaneous competition and cooperation ('coopetition'). Customers work with a network of alliances to agree on solutions - there is little room for dominant (and domineering) brands in this framework.

Futurologists have tended to argue most confidently for this radical view. Their revolutionary rhetoric is impressive, often mind-blowing. But - it has to be said - they have not been overly precise about how, and how much, the Internet will change our lives.

\section{IT IS NOT THAT DIFFERENT - EXCEPT WHERE IT IS!}

The alternative view is far more circumspect. It tries to prise apart reality from hyperbole. Advocates of this view point out the following.

- Business fundamentals still apply. Michael Dell of Dell Computers recently emphasised that the key to successful application of Internet technologies within modern businesses is to maintain a focus on basic business fundamentals such as liquidity, profitability and growth. ${ }^{16}$ Even Gary Hamel - a revolutionary at heart - has argued much the same, pointing out that the Internet is the enemy of profit - a strong statement, but none the less a highly pertinent one. ${ }^{17}$ Attention to costs, communication, fulfilment - these marketing fundamentals are ignored at one's peril.

- Traditional marketing practices are still very much alive. One need only look at the way dot.coms have promoted themselves using conventional media such as newspapers, magazines and television. Furthermore, these dot.coms have faced familiar physical and logistic constraints when attempting to fulfil orders and deliver goods and services. As Nick Higham observed: 'Online retailing of the kind practised by Amazon isn't very different from conventional mail-order - with the crucial exception that customers enter the order themselves. ${ }^{18}$

- A desire on the part of managers to build closer relationships with customers pre-dates the Internet. The story here appears to be one of continuity, in that there 
has been a gradual rediscovery of relationship marketing, based on the substitution of personal communication by capital-intensive technology-based communication (eg direct mail, call centres, ATMs and automated bill payment systems). Similar concerns arise in both the old and new worlds - do customers want relationships, should they be expected to give permission, is technologybased communication quality communication?

- More and more, we are finding that the future lies with 'clicks and mortar'. A recent survey of large European corporates and Web startups found that both these types of business are converging on the view that the future lies in clicks and mortar. ${ }^{19}$ This would tend to favour established brands that can extend their operations into the world of e-business, and e-business organisations that can build effective brands in a conventional sense.

- Many of the fears for the future of branding and brand management are not new. Brand managers have always had to contend with the pressure to commodify markets the Internet does not remove this pressure, but nor does it make the process of commodification inevitable. Balancing the demands of customisation and standardisation has always been a challenge for brand managers - recall that $\mathrm{H}$. J. Heinz has 57 varieties, not one for all.

- Internet-like networks have been around for quite some time, which means some of us have 20-30 years' experience of these technologies. Nor was the Internet the first technology to be commercialised with the result of imploding distance and enhancing communications. In their day, railways, automobiles, aircraft, the telegraph, fax machines and telephones all had this effect.

The viewpoint that 'it is not different - except where it is' is nicely expressed by Philip Evans and Thomas Wurster $^{20}$ (see also the review by Alan Mitchell). ${ }^{21}$ As BCG consultants they started out with quite a revolutionary frame of mind. They were thinking about chaos, disintermediation, deconstructing supply chains and deconstructing the organisation, but they were taken in a surprising direction. 'We quickly found that many, if not most, of the traditional principles of strategy apply in the 'new' [world] much as they do in the old. Economies of scale, segmentation, and cost position all still work.' What has changed is the 'glue' that holds many components of business together; namely, information flows. Evans and Wurster claim that this glue is dissolved by new technologies, but perhaps it would be more appropriate to say it circulates with greater ease and speed among a wider number of people than ever before, rather than say it has dissolved altogether.

A very similar stance is emerging from one of Europe's new media 'think-tanks', the Future Media research programme at London Business School. Four years ago, director of the centre Patrick Barwise wrote: 'In short, brands are here to stay. Their role could even increase over time as our society becomes even more over-communicated. $^{22}$ According to Barwise and Kathy Hammond more recently, 'noth- 
ing that has happened since would cause us to doubt this verdict'. ${ }^{23}$

\section{LET US SEE THE EVIDENCE}

The focus of this special issue is the impact of interactive electronic marketing on brands and brand management. What the foregoing shows is that there certainly has been an impact. If there was any doubt. But what kind of impact? Do brands as we have come to know them continue to matter in e-business? What aspects of branding change - if any — when attention shifts to interactive electronic marketing? Is co-branding on the Web different from normal co-branding practices? Are patterns of consumer loyalty to brands different in cyberspace? How do well-established organisations manage mixed portfolios of offline and online brands? What implications are there for the organisation of brand management functions within organisations, including networked ones? Many new e-brands appear to be playing by different rules - but are they? Are online-only organisations at an advantage, or are we to expect most successful players to operate clicks and mortar? With the advent of e-business are we finally able to create true global brands? Or, by total contrast, does e-business imply increasing fragmentation and disintegration - lessening the chances of there ever being truly global brands? These are just some of the questions being asked by managers and researchers today.

Currently there is little agreement on the answers, despite all the activity listed above and the firmly expressed views of revolutionaries and evolutionists. Rather too much of this work has been speculative, crystal-ball gazing and soothsaying. Where formal research has been undertaken, much of it has been descriptive and ad hoc. As already shown, case histories have been widely reported — with a focus on best practice. While there is a place for this kind of work, we also need rigorous and systematic empirical research. Only then will we be confident of the principles we espouse. Only then will we have reliable knowledge on which to base investment and business decisions. As Donna Hoffman notes: 'Until we have such information, development will be dictated largely by fear, confusion, and a 'gold-rush' mentality. ${ }^{24}$ There are encouraging signs that this message is being heard. Empirical papers in this issue provide a few examples, and a broad-based survey of the research evidence has been compiled by Patrick Barwise, Kathy Hammond and Anita Elberse. ${ }^{25}$

\section{THE PAPERS}

\section{Management principles}

Many of these issues and debates are reflected in the selection of papers published in this special issue.

Alan Mitchell challenges us to stop and think about commonly accepted practices and notions from a fresh point of view. He argues that none of the hallmarks of industrial-age brand management - its preserve as a seller's monopoly, its seller-centricity, or the stimulus-response methodologies that it routinely employs - can survive intact in the new era of interactive electronic marketing. Some will regard this as threatening. Mitchell, however, sees it as an opportunity for the impact of 
marketing to be much greater. Where marketing has established a relationship between buyers and sellers, it is possible for there to be an exchange of information. Marketing is a quintessential information-processing activity. This exchange then can form the basis of more effective and relevant customisation of services, products, solutions and further information. Ideally, it is a win-win wealth-creation spiral.

Noah Shannon and Robert Clauser comment on similar themes, but they are more cautious and circumspect about the future. Their approach is to present five familiar offline branding rules and consider the implications in terms of online tools. They look at brand naming, the consistency of brand messages and images, the importance of delivering on the promise, customer insights, and emotional connections between brands and consumers (for instance, with respect to personalisation and co-creation). They conclude that 'although new technologies and media have equipped brand management with additional tools, the fundamental rules of brand building have not changed'. The brand manager is advised to follow these rules carefully, and break them cautiously.

Stephen Chen weighs up the evidence for the claim that ecommerce will spell the end of brand management as we know it. He finds the claim wanting. Brands serve different purposes and roles, and vary by type of product and type of purchase, so it is to be expected that the impact of e-commerce will depend on the context. Moreover, ecommerce itself is not monolithic the Internet supports the Web, but also discussion groups, communication systems, etc. Each of these technologies may have a differential impact. The effect of information search and retrieval technologies (ie search engines, comparison shopping sites and co-branding) may be quite different from personalisation technologies (ie cookies, mailing lists and push technologies), and different again from online communities. In turn, there are changes in market structure and power (eg additional levels in the supply chain in some cases and disintermediation elsewhere). The overall message is that while some brands will win and others lose, the basic brand management principles and lessons from the offline world should not be ignored.

\section{Empirical studies}

Four academic papers take up the call for empirical studies. Of necessity, they are far more specific than the first three papers.

Koen Pauwels and Enrique Dans provide a fascinating study of the leveraging of brand equity from offline to online newspapers. Hypotheses are tested regarding the dynamics of digital markets (in terms of digital visits and page views) and brand equity transfer (mainly in terms of audience size and audience profile). They find the popularity of online newspapers is influenced both by the audience size of its printed edition, and by its profile fit with that of the typical Internet user. Thus, offline brand equity appears to carry across to online newspapers but the extent of carryover depends on whether it is a mass circulation general newspaper or a specialist one with, say, a financial or sports focus. Also, there are crucial competitive dynamics to consider - especially where a number of newspapers compete for similar 
advertisers. This is exactly the kind of detailed empirical research that is needed if we are to move beyond mere speculation. The approach taken by Pauwels and Dans illustrates a pragmatic blend of the old and the new familiar printed newspapers and new online services, familiar forms of data analysis, but applied to new measures of digital visits and page views.

The next two papers focus on aspects of corporate branding. Mission and vision statements are widely used to help companies position themselves and express their corporate goals. Rosa Chun and Gary Davies examine this topic from the stance of these statements on the websites of US computer manufacturers, specialist retailers and commercial banks. It is found that while most sites include these statements, the content is often not transparent and the information is time-consuming to access. If corporate branding goals are to be achieved online, managers and website designers need to pay greater attention to the content and accessibility of such material. These concerns are challenging enough in the offline world, but it is perhaps harder online where - typically - suppliers, customers, employees and shareholders all have access to the same site. In such circumstances the issue of content consistency is bound up with website design and ease of navigation.

In a related paper, Foo Check-Teck reports on a preliminary study of corporate e-logos. Empirical results thus far show that complexity - in the form of more letters, words, etc — might add to attractiveness, whereas the use of more colour or more symbols might not. Foo suggests further empirical work is required before drawing definitive con- clusions, but the underlying case is for more formal testing of corporate elogos than hitherto. A broader interpretation is that the rise of e-commerce presents brand managers and designers with an opportunity - or excuse - to re-evaluate the core aesthetic and visual elements of their brands.

An increasing number of papers are being published on e-branding and Internet advertising. A theme here is why and how Internet ads should be used in conjunction with traditional media. Sung-Joon Yoon and Joo-Ho Kim address this topic by taking a consumer perspective - given different consumer types (rationally oriented consumers, etc) and different product categories with varying levels of consumer involvement, they ask which media are consulted, how often, and why? To an extent the answer depends on the mix of media that managers choose to put before consumers - but ideally these decisions should be made hand in hand with an understanding of consumer behaviours, attitudes and motives. The next step would be to relate this to specific brand choices, not just product category choices, although we may find there is little difference in media choice/use among directly competing brands (in line with offline experience).

\section{Commentaries and book reviews}

The special issue concludes with a commentary and two book reviews.

Martin Lindstrom, chief operating officer of BT LookSmart, is very well placed to reflect on some of the most pressing dilemmas facing brand managers today. One of the most crucial is 'going international' with your brand. The tone of his comments 
is upbeat and positive - 'the dream of a truly global brand could yet become a reality'. But, like several other contributors, Lindstrom voices a note of caution. While technology can in principle make worldwide brand building easier, success depends on working effectively with people, and that requires cultural sensitivity, localisation as well as globalisation, and a one-to-one relationship of trust with each user. Sound advice.

From among the many dozens of e-commerce books that are flooding on to the market, two have been selected for review. In many ways they are typical. 'Breaking Compromises' offers insights based on the ringside position of a team of BCG consultants; 'Internet Marketing' has more of the feel of a textbook, but with input from business professionals as well as academics. Both are replete with examples and short cases, but as our reviewers - Grahame Dowling and Kelly Page - point out, there is a need for greater depth in the case-study material and a more thorough attempt to substantiate the espoused principles. All too often, it seems, we are left asking 'let's see the evidence'.

Collectively, the work presented in this special issue illustrates the type of research that is currently being undertaken. Some of it is broad-brush and strategic in nature. Other studies are more specific, with the aim of providing very concrete and definitive findings. In these ways we will come to answer at least some of the questions posed earlier. This should help in terms of creating an understanding of interactive electronic marketing, and provide better frameworks, principles and benchmarks for brand management.
Papers were refereed by a panel of expert reviewers. We are most grateful for their advice and support.

\section{Mark Uncles Special Issue Editor Journal of Brand Management \\ March 2001}

\section{References}

(1) Hoffman, D. L. and Novak, T. P. (1996) 'Marketing in hypermedia computer-mediated environments: Conceptual foundations', Journal of Marketing, No. 60, July, pp. 50-68.

(2) Barwise, P. (1997) 'Editorial: Brands in a digital world', Journal of Brand Management, Vol. 4, No. 4, February, pp. 220-223.

(3) Kapferer, J.-N. (2000) 'Editorial: How the Internet impacts on brand management', Journal of Brand Management, Vol. 7, No. 6, pp. 389-391.

(4) Kalakota, R. and Whinston, A. B. (1999) 'Electronic Commerce: A Manager's Guide', Addison-Wesley, Reading MA.

(5) Watson, R. T., Berthon, P., Pitt, L. F. and Zinkhan, G. M. (2000) 'Electronic Commerce: The Strategic Perspective', Dryden Press, Fort Worth.

(6) Timmers, P. (1999) 'Electronic Commerce: Strategies and Models for Business-toBusiness Trading', John Wiley, Chichester.

(7) Bickerton, M., Bickerton, P. and Pardesi, U. (2000) 'Cybermarketing: How to Use the Internet to Market Your Goods and Services', 2nd edn, Butterworth-Heineman, Oxford.

(8) Hanson, W. (2000) 'Principles of Internet Marketing', South Western College Publishing, Cincinnati.

(9) Reedy, J., Schullo, S. and Zimmerman, K. (2000) 'Electronic Marketing: Integrating Electronic Resources into the Marketing Process', Dryden Press, Fort Worth.

(10) Benchmark Communication (2000) 'Best Practice in E-commerce', Benchmark Communication, Auckland, New Zealand, see http://www.best-practice.com.

(11) Lindstrom, M. and Andersen, T. F. (2000) 'Brand Building on the Internet', Kogan Page, London.

(12) Evans, P. and Wurster, T. S. (1999) 'Blown to Bits: How the New Economics of Information Transforms Strategy', Boston Consulting Group and Harvard Business School Press, Boston.

(13) The Economist (1994) 'Death of the brand 
manager', The Economist, 9th April.

(14) Sheth, J. and Sisodia, R. S. (1999)

'Revisiting marketing's lawlike generalizations', Journal of the Academy of Marketing Science, Vol. 27, No. 1, pp. 71-87.

(15) Dayal, S., Landesberg, H. and Zeisser, M. (2000) 'Building digital brands', The McKinsey Quarterly, No. 2, pp. 42-51.

(16) Dell, M. (2000) speech at London Business School, June, see http://www.london.edu/ news_events.

(17) Hamel, G. (2000) 'Leading the Revolution', Harvard Business School Press, Boston.

(18) Higham, N. (1999) 'Amazon success story built on traditional marketing expertise', Marketing Week, 14th October, p. 17.

(19) Rosen, N. and Barwise, P. (2000) 'Business.eu - Corporates vs Web Start-ups', London Business School and Protégé, London.
(20) Evans and Wurster, ref. 12 above.

(21) Mitchell, A. (1999) 'Why major brands may come unstuck on the Web', Marketing Week, 14th October, pp. 40-41.

(22) Barwise, ref. 2 above, p. 223.

(23) Future Media research programme (2000) update on 'Brands in a Digital World', http://www.london.edu/marketing/future/.

(24) Hoffman, D. L. (2000) 'The revolution will not be televised: Introduction to the special issue on marketing science and the Internet', Marketing Science, Vol. 19, No. 1, pp. 1-3.

(25) Barwise, P., Hammond, K. and Elberse, A. (2001) 'Marketing and the Internet: A research review', in Weitz, B. A. and Wensley, R. (Eds) 'Handbook of Marketing', Sage, Beverley Hills (forthcoming), see http://www. marketingandtheinternet.com. 